\title{
Evaluation of Photodegradation in LDPE/modified Starch Blends
}

\author{
Flávia G. D. Ferreira, Maria A. G. A. Lima, Yêda M. B. Almeida, Glória M. Vinhas \\ Departamento de Engenharia Química, Universidade Federal de Pernambuco
}

\begin{abstract}
Photodegradation of LDPE/modified starch blends $80 / 20 \mathrm{~m} / \mathrm{m}$ has been examined by scanning electron microscopy (SEM), Fourier transform infrared spectroscopy (FTIR) and X ray diffraction (DRX) before and after exposure to ultraviolet radiation (UV). Samples were exposed to UV in the laboratory for periods of 6, 24, 48 and 60 hours. The main alteration in the polymeric material after exposure to the radiation was a decrease in the mechanical properties, tensile strength and elongation. There were also changes in the chemical structure of the blend with an increase in the carbonyl and vinyl indices, 65.58 and $53.29 \%$, respectively. The analysis of the blend crystallinity pointed to the formation of a new crystalline symmetry that did not exist before the irradiation.
\end{abstract}

Keywords: Photodegradation, polymer blends, polyethylene, starch.

\section{Introduction}

The wide use of polymers in many industrial and domestic fields causes ecological problems connected with their utilization. Some synthetic plastics including polyolefins, as polyethylene, are characterized by relatively high stabilities under both photochemical and environmental conditions. The use of natural or synthetic photo and biodegradable polymers is promising ${ }^{[1]}$.

Many ideas have been proposed for controlling the lifetime of plastics and acceleration of their decomposition for the purpose of waste reduction. The blending of stable synthetic polymers with biopolymers and the chemical or physical modification of polymeric composites are examples of solutions used for inducing degradability ${ }^{[2]}$. Biodegradable polymer films have been made from low density polyethylene (LDPE), rice and potato $\operatorname{starch}^{[3,4]}$.

Starch, an omnipresent biomaterial, is one of the most abundant and inexpensive polysaccharide sources which have the unique characteristic of biodegradability and easily dissolve in water ${ }^{[5,6]}$. Blends of starches with synthetic polymers have been extensively studied to develop a material partially or totally biodegradable ${ }^{[7-10]}$.

In the presence of sunlight, polymeric material undergo a series of reactions, such as photolytic, photo-oxidative, and thermo-oxidative, that result in the degradation of the material leading to chemical degradation, with consequences such as brittleness, loss of the brightness, colour change, opacity and the formation of surface cracks $^{[1]]}$. During UV irradiation of polymers, activated molecules are formed in first step and then various processes, such as chain scission, cross-linking and oxidation, take place in the second. The main scission will first cause of photodissociation and then radical formation. If the free radicals can migrate and recombine with other radicals or the main chain, cross-linking will occur ${ }^{[12]}$. Besides the reduction in molecular weight, a number of changes take place in the molecules during photodegradation with the formation of chemical groups like carbonyl, carboxylic acids and hydroperoxides ${ }^{[13,14]}$.

In this work, the effect of photodegradation at different exposure times was investigated. The LDPE/modified starch blends were exposed in the laboratory and mechanical properties, chemical changes and degree crystallinity were tested.

\section{Experimental}

\section{Materials}

Low density polyethylene (LDPE), EB-853, with a flow index of $2.7 \mathrm{~g} / 10$ minutes $\left(190^{\circ} \mathrm{C} / 2.160 \mathrm{~kg}\right)$, was supplied by BRASKEM. The starch used was Foxhead ${ }^{\circledR}$ 5901, amphiprotic type, made up of $27 \%$ amylose and $73 \%$ amylopectin, supplied by Corn Products Brazil.

\section{Blend preparation}

The LDPE/modified starch blends, with a composition of $80 / 20 \mathrm{w} / \mathrm{w}$, were obtained by melt mixing in the mixture chamber of a HAAKE rheometer, under the following conditions: $50 \mathrm{~g}$, temperature at $140{ }^{\circ} \mathrm{C}$, maximum torque $50 \mathrm{Nm}$, rotor rate $50 \mathrm{rpm}$, and mixing time 10 minutes. After blend was triturated in a grinding rotor axis, and its films were obtained in an hydraulic press, with a thickness of $0.175+0.025 \mathrm{~mm}$, in the following conditions: force 8 ton, time compressed for 1 minute, plates temperatures in a $140{ }^{\circ} \mathrm{C}$ and mold with $400 \mathrm{~cm}^{2[15]}$.

Autor para correspondência: Glória M. Vinhas, Departamento de Engenharia Química da Universidade Federal de Pernambuco, Av. Prof. Artur de Sá, s/n, CEP: 50740-521, Recife, PE, Brasil.E-mail: gmvinhas@yahoo.com.br 


\section{Exposure of the blends to ultraviolet radiation}

The source of UV radiation was fluorescent tubes Cleo-65 $80 \mathrm{~W}-\mathrm{R}^{[16]}$. This type of UV source is normally used for artificial sunbath and corresponds reasonably well to sunlight. The distance between lamp and sample was set at $75 \mathrm{~mm}$ and the exposure was conducted at a constant temperature room of $23{ }^{\circ} \mathrm{C}$ with a radiation intensity of $2 \mathrm{~W} \cdot \mathrm{m}^{-2}$. The samples had been displayed at intervals of 6, 24, 48 and 72 hours. The exposure to ultraviolet radiation was carried out in the Department of Engineering of Materials of the Federal University of Campina Grande - Brazil.

\section{Mechanical properties}

The mechanical properties of the samples carried out in a EMIC DL 500 MF Universal Testing Machine following ASTM D 638-03 ${ }^{[17]}$. The measurements were conducted for each sample and the results were averaged to obtain a mean value of tensile strength and percentage elongation.

\section{Scanning electron microscopy (SEM)}

Samples ruptures during mechanical test were observed using a microscope JEOL JSM-6360 with increases of 100 and 250 times.

\section{Fourier transformed infrared spectroscopy (FTIR)}

The FTIR spectra were measured with a Brucker 1FS66 using the $\mathrm{KBr}$ tablet technique. Spectra were obtained in region of $500-4000 \mathrm{~cm}^{-1}$.

\section{$X$ ray diffraction}

The $\mathrm{X}$ ray diffraction was carried out with a Siemens Model D-5000 diffractometer using $\mathrm{Cu}$ in diffraction angle $2 \theta^{\circ}$ : $5-40^{\circ}$, and scanning rate: $0.04^{\circ} 2 \theta /$ seconds.

\section{Results and Discussion}

\section{Mechanical properties}

In Figure 1, a significant increase in tensile strength is observed after 60 hours of exposure to UV radiation, compared with samples exposed for 6, 24, 48 and 72 hours. Although the number of exposure intervals is not large enough to provide a conclusive picture of this behavior, it is possible

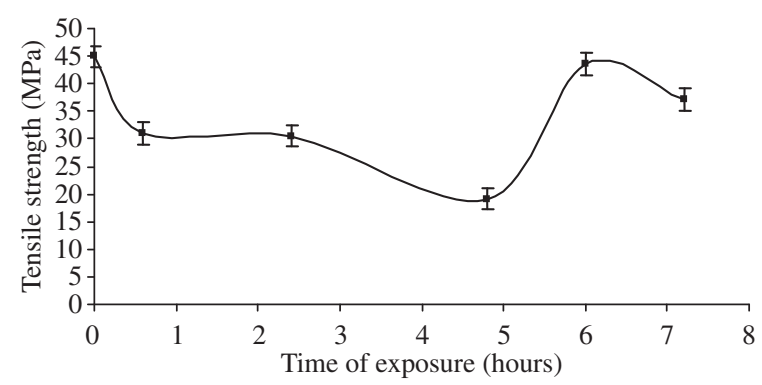

Figure 1. Tensile strength (MPa) depending on the time of exposure to ultraviolet radiation from LDPE/modified starch blends.

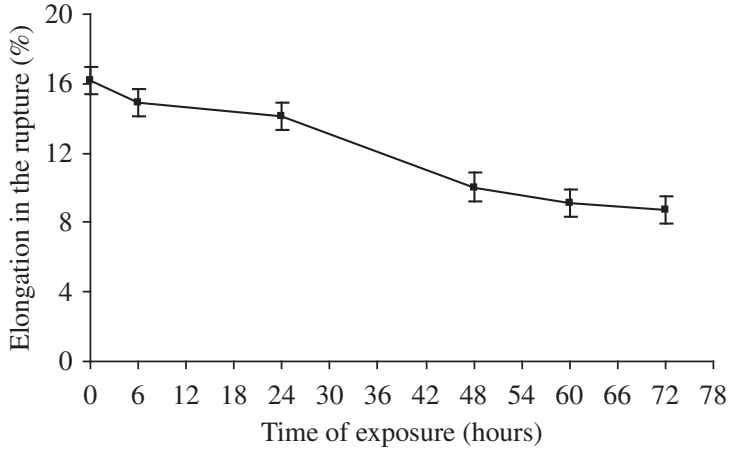

Figure 2. Elongation in the rupture (MPa) depending on the time of exposure to ultraviolet radiation from LDPE/modified starch blends.

that this partial recovery in properties is a result of a very fragile surface layer that is unable to transmit stress into the underlying material, due the components of imisibility of the blend. Another possibility is that the crosslinking reactions between the chains may occur along with the scission reactions, or there is competition between crosslinking and scission reactions of such chain, because of photochemical degradation, which may have promoted some stability in mechanical properties ${ }^{[18,19]}$.

The elongation at up showed a significant decrease in relation to the time of the ultraviolet radiation exposure of the LDPE/modified starch blends as can be seen in Figure 2 . This is a typical behavior of semi-crystalline polymer which is submitted to reactions from broken links of molecules, after a long time of exposure to radiation, causing weakness of the samples.

The change in the chemical structure of LDPE/modified starch blends, after exposure to ultraviolet radiation, results in the formation of new groups in the polymer chain, carbonyl and vinyl groups for example, mainly in the amorphous region of material, and this may be ones of the causes responsible for the decrease the mechanical properties ${ }^{[19]}$. The break in the polymer chains causes the decrease in percentage elongation of material, resulting in more fragile material.

\section{Scanning electron microscopy (SEM)}

The analyses of SEM microphotographs of the fracture surfaces samples of LDPE/modified starch blends, before and after exposure to ultraviolet radiation, illustrated in Figures 3 and 4.

Observing the microphotographs presented in Figure 3, it can be verified that the rupture of the samples, which had not been exposed to ultraviolet radiation occurred in ductile form. This is evident by the formation of "fibrillas" typical of a material that presents a certain elongation at break up when submitted to tensile. When the same material is exposed to ultraviolet radiation, however, it is evident that the "fibrillas" diminish, as characteristic of a less elastic material, presenting less elongation before breaching and therefore more fragility, as shown in Figure 4. 


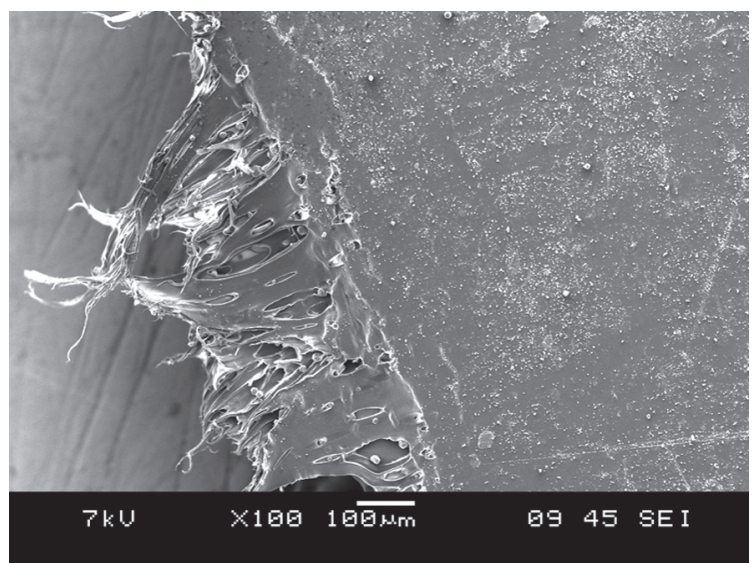

(a)

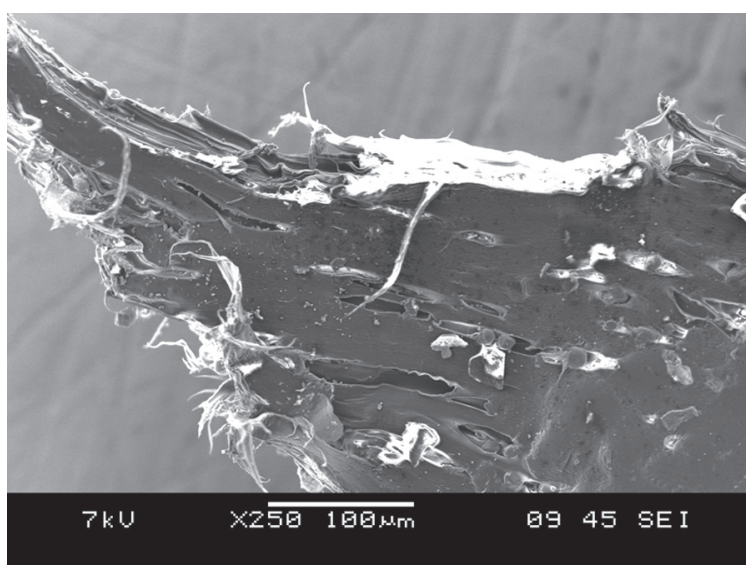

(b)

Figure 3. SEM microphotographs of fracture surfaces from the LDPE/modified starch blends before exposure to ultraviolet radiation with an increase of a) $100 x$; and b) $250 x$.

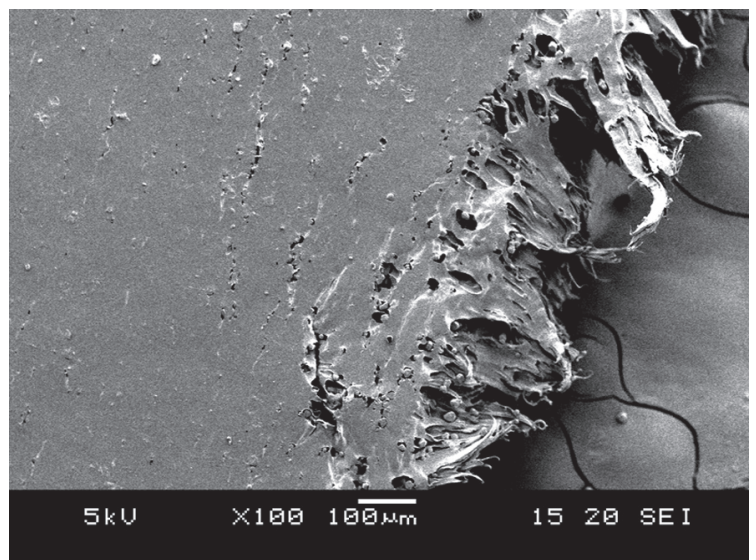

(a)

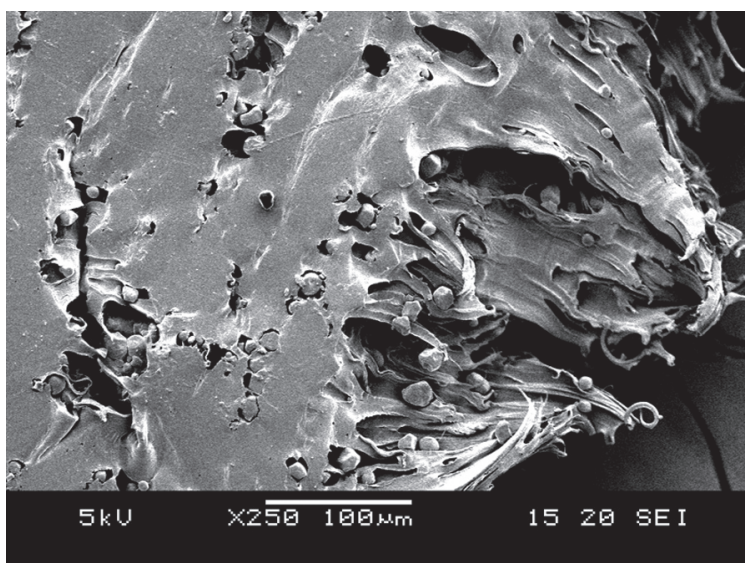

(b)

Figure 4. SEM microphotographs of fracture surfaces from the LDPE/modified starch blends after 72 hours of exposure to ultraviolet radiation with an increase of a) $100 x$; and b) $250 x$.

\section{Fourier transformed infrared spectroscopy (FTIR)}

The photodegradation causes change in the molecular structure of polymers by generation chemical groups like carbonyl $(-\mathrm{C}=\mathrm{O})$, hydroxyl $(-\mathrm{OH})$ and vinyl $(-\mathrm{CH}=\mathrm{CH}-)$ groups, this behaviour is characteristic of degradation of the material ${ }^{[18,19,23]}$.

Figures 5 and 6 show the increase of carbonyl and vinyl groups in LDPE/modified starch blends after different times of exposure to UV radiation. The structural changes of LDPE/modified starch blends after exposure to UV radiation can be detected by FTIR. To quantify the structural change that blends suffered during exposure to ultraviolet radiation, the carbonyl and vinyl index of ones was determined.

Figure 5 shows the results of carbonyl index which was calculated on the basis of the carbonyl band at $1715-1740 \mathrm{~cm}^{-1}$ (due to carbonyl stretching vibrations) gotten in accordance with the area of carbonyl absorption band of FTIR spectrum for each time of irradiation, and occupied the absorbance area corresponding to the band at $2970 \mathrm{~cm}^{-1}$ (stretching C-H) as reference, according to the Equation $1^{[20]}$. After 72 hours of exposure to visible

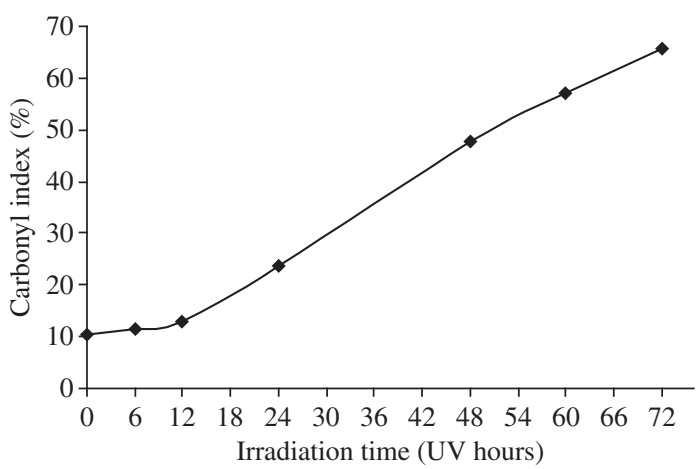

Figure 5. Index of carbonyl depending on the time of exposure to ultraviolet radiation from LDPE/modified starch blends.

ultraviolet light the carbonyl index (IC) and the vinyl index (IV) showed an increase of 65.58 and $53.29 \%$, respectively, when compared with the samples that had not been exposed to $\mathrm{UV}$ radiation.

$$
\mathrm{IC}=\frac{\left(\text { area of absorbance } 1715 \mathrm{~cm}^{-1}\right)}{\left(\text { area of absorbance } 2970 \mathrm{~cm}^{-1}\right)} \cdot 100
$$




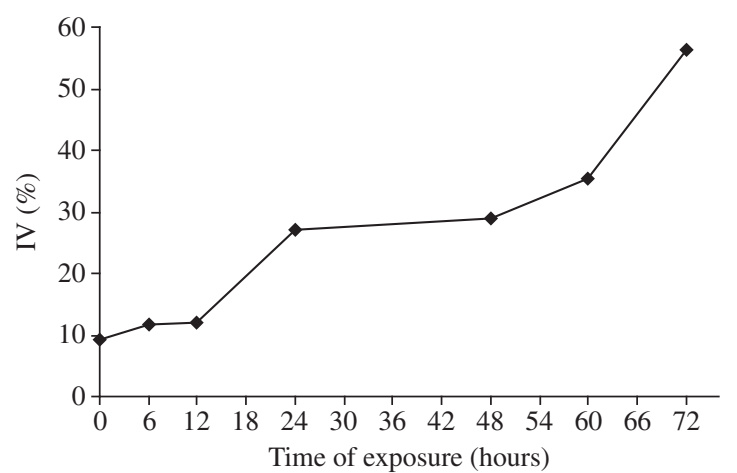

Figure 6. Index of vinyl depending on the time of exposure to ultraviolet radiation from LDPE/modified starch blends.

The vinyl index was calculated on the basis of the vinyl band at $1640-1680 \mathrm{~cm}^{-1}$ (due to vinyl stretching vibrations) gotten in accordance with the area of vinyl absorption band of FTIR spectrum for each time of irradiation, and occupied an absorbance area corresponding to the band at $2970 \mathrm{~cm}^{-1}$ (stretching $\mathrm{C}-\mathrm{H}$ ) as reference, according to the Equation $2^{[20]}$, the results of which are presented in the Figure 6 .

$$
\mathrm{IV}=\frac{\left(\text { area of absorbance } 1640 \mathrm{~cm}^{-1}\right)}{\left(\text { area of absorbance } 2970 \mathrm{~cm}^{-1}\right)} \cdot 100
$$

According to Figures 5 and 6, the data confirmed the degradation through carbonyl or vinyl group formation and generation which are the main evident products resulting from the broken chains due to photodegradation in the blends. It was also observed that different irradiation times cause increase of the carbonyl and vinyl bands absorption.

\section{$X$ ray diffraction}

The determination of the fraction crystalline or degree of crystallinity is an important parameter to define the chemical and physical properties of polymer material. The degree of crystallinity, presented in Table 1, was calculated for the area under the diffracted peaks, discounting the amorphous halo area of the polymer material, in accordance with Equation $3^{[21]}$.

$$
\% \mathrm{C}=\frac{\mathrm{I}_{\mathrm{c}}}{\left(\mathrm{I}_{\mathrm{c}}+\mathrm{KI}_{\mathrm{a}}\right)} \cdot 100
$$

where $\% \mathrm{C}$ is crystalline fraction, $\mathrm{I}_{c}$ is the result of the integration of the diffraction peaks, $I_{a}$ is a result of the integration of the amorphous halo, obtained through the Gaussiana approach of the diffractogram and $\mathrm{K}$ is a constant of the characteristic proportionality of each polymer, in this case polyethylene, $1.23^{[21]}$. The data referring to the subtraction of the amorphous halo was obtained using the Gaussiana approach (Table 1).

The ability of a material to diffract an $\mathrm{X}$ ray beam in certain directions is associated with its crystalline reticulum.
Table 1. Parameters of the calculation of crystallinity and crystalline fraction $(\% \mathrm{C})$ the LDPE/modified starch blends exposed to ultraviolet radiation.

\begin{tabular}{cccc}
\hline $\begin{array}{c}\text { Time of } \\
\text { exposure } \\
\text { (hours) }\end{array}$ & $\begin{array}{c}\text { Integral of } \\
\text { diffractogram }\end{array}$ & $\begin{array}{c}\text { Area } \\
\text { (Gaussiana } \\
\text { approach) }\end{array}$ & \% C \\
\hline 0 & 1121.62 & $958.89 \pm 18.82$ & 48.74 \\
6 & 866.41 & $735.88 \pm 13.21$ & 48.90 \\
24 & 1480.33 & $758.61 \pm 24.43$ & 61.34 \\
48 & 1501.48 & $751.96 \pm 54.97$ & 61.78 \\
60 & 1518.74 & $759.98 \pm 63.76$ & 61.90 \\
72 & 1588.54 & $774.16 \pm 14.26$ & 67.73 \\
\hline
\end{tabular}

The degree of crystallinity showed an increase according to the exposure time to ultraviolet radiation. This fact reinforces the hypothesis that fragments of molecules in the amorphous region and of binding molecules which are rearranged on the crystallites, causing an increase in the degree of crystallinity of polymer material ${ }^{[22]}$.

\section{Conclusions}

The effect of ultraviolet radiation in samples of LDPE/modified starch blends was analyzed using several techniques. In the mechanical test, properties such as tension at break up and the percent of elongation indicated a direct correlation to the increased exposure time of ultraviolet radiation to blends. The SEM confirmed the fragility of the material, when they were considered the microphotographs the region of fracture surfaces blends after exposure to radiation were considered. The reduction of "fibrillas" in the region indicated of elasticity of the material.

The analysis of FTIR indicated an increase in carbonyl and vinyl groups present in blends. This fact indicated the process of degradation suffered by the material due to exposure to ultraviolet radiation. Another important factor was the increase in crystallinity of blends, due to the decrease of the polymer chains preferably the amorphous region, and the rearrangement of these molecules causing a larger organization of the chains and thus increasing the region of crystalline material.

\section{Acknowledgements}

We would like to thank Dr. L. Hecker, Dr. S. M. de L. Silva and Dr. M. S. Rabello (DEMA - Federal University of Campina Grande-Brazil) for allowing the use of their laboratory and equipment for the preparations of the blends, Braskem and Corn Products Brazil for supplying the LDPE and starch, respectively, and the Analytical Central of the Chemistry Department at the Federal University of Pernambuco - Brazil. We also gratefully acknowledge the financial support from CAPES, FACEPE and CNPq. 


\section{References}

1. Oldak, D.; Kaczmarek, H.; Buffeteau, T. \& Sourisseau, C. - J. Mater. Sci., 40, p.4189 (2005).

2. Kaczmarek, H. \& Oldak, D. - Polym. Degrad. Stab., 91, p.2282 (2006).

3. Arvanitoyannis, I.; Biliadois, C. G.; Ogawa, H. \& Kawasaki, N. - Carbohydr. Polym., 36, p.89 (1998).

4. EL-Rahim, H. A. A.; Hegazy, E. S. A.; Ali, A. M. \& Robic, A. M. - J. Photochem. Photobiol. A, 163, p.547 (2004).

5. Cascone, M. G.; Barbani, N.; Cristalini, C.; Ginsfi, P.; Ciardelli, G. \& Lazzari, L. - J. Biomater. Sci. Polym., 12, p.267 (2001).

6. Zhai, M.; Yoshii, F.; Kume, T. \& Hashim, K. - Carbohydr. Polym., 50, p.295 (2002).

7. Arvanitoyannis, I. S. - J. Macromol. Sci. Part C: Rev. Macromol. Chem. and Physics, C39, p.205 (1999).

8. Graaf, R. A.; Janssen, L. P. B. M. - Polym. Eng. Sci., 34, p.2 (2000).

9. Graaf, R. A.; Janssen, L. B. P. M. - Polym. Eng. Sci., 41, p.3 (2001).

10. Kaplan, D. L. - "Biopolymers from renewable resources". Springer, Berlin (1998).

11. Andrady, A. L.; Hamid, S. H.; Hu, X. \& Torikai, A. - J. Photochem. Photobiol. B, 46, p.96 (1998).

12. Tse, K. C. C.; Ng, F. M. F. \& Yu, K. N. - Polym. Degrad. Stab., 91, p.2380 (2006).
13. Carlsson, D. J. \& Wiles, D. M. - J. Macromol. Sci., Part C: Rev. Macromol. Chem. and Physics C14, p.65 (1976).

14. Fechine, G. J. M.; Rabello, M. S. \& Souto-Maior, R. M. - Polym. Degrad. Stab., 75, p.153 (2002).

15. Lima, S. M. - "Estudo da Capacidade Biodegradadora de Culturas Mistas de Fungos em Blendas Poliméricas Biodegradáveis", Msc. Dissertation, Federal University of Pernambuco, Brazil (2005).

16. Rabello, M. S. \& White, J. R. - Plast. Rubber Compos. Process. Appl., 25, p.237 (1996).

17. American Society for Testing and Materials - ASTM "Test Method for Tensile Properties of Plastics" (Test Method D638-03), Annual Book of ASTM Standards, West Conshohocken, Pennsylvania (2003).

18. Sousa, A. R.; Amorin, K. L. E.; Medeiros, E. S.; Melo, T. J. A. \& Rabello, M. S. - Polym. Degrad. Stab., 91, p.1504 (2006).

19. Coelho, N. S.; Almeida, Y. M. B. \& Vinhas, G. M. Polímeros - Cienc. Tecnol., 18, p.270 (2008).

20. Canevarolo Jr, S. V. - "Técnicas de Caracterização de Polímeros", Artliber Editora Ltda, São Paulo (2003).

21. Luo, S. \& Netravali, N. - J. Appl. Sc., 73, p.1059 (1999).

22. Sánchez-Solís, A. \& Estrada, M. R. - Polym. Degrad. Stab., 52, p.305 (1996).

Enviado: 03/06/09

Reenviado: 09/09/09

Aceito:15/09/09 